\title{
Economic Analysis of Hydraulic Supports in China and Abroad
}

\author{
Songlin Li \\ School of Management, China University of Mining \& Technology (Beijing), Beijing 100083, China. \\ 1152053083@qq.com
}

Keywords: Hydraulic support; economy; comparative analysis.

\begin{abstract}
Based on the economic analysis theory of equipment life cycle,7 indicators were used as indicators to evaluate the economical efficiency of hydraulic support,34 sets of domestic hydraulic support and 20 sets of foreign hydraulic support were used as samples to compare the economic performance of hydraulic support made by China and abroad.The results show that although the cost-effectiveness of domestic hydraulic supports is high,its reliability and stability are poor,the failure rate is high,and the cost of spare parts materials and overhaul are high,resulting in weaker economic indicators of domestic hydraulic support than abroad.
\end{abstract}

\section{Introduction}

With the continuous improvement of China's coal mining technology, the application of three machines in the fully mechanized mining face is becoming more and more extensive[1].The three-mechanized mining face includes coal mining machine, scraper conveyor and hydraulic support, The hydraulic support as one of the major equipment to comprehensive mechanized coal mining, it is crucial in underground coal mining work[2-3].In recent years, domestic hydraulic supports have been greatly improved in the design and manufacturing process level. Domestic large-scale mines also increasingly use domestic hydraulic supports, but domestic hydraulic supports still have many problems such as poor stability, there still exists a considerable gap between domestic and abroad hydraulic supports [4]. This article will compare the economic indicators of domestic and foreign hydraulic supports, in order to find the inadequacies of domestic hydraulic support, so as to provide reference for localization of hydraulic support.

\section{Hydraulic Support Economic Indicators}

The advantages and disadvantages of equipment economy are the main reference for customers to choose whether to purchase such products, However, it is difficult to reasonably measure the economic efficiency of equipment, this article is based on the economic analysis of equipment life cycle decrypting 34 sets of domestic and 20 sets of imported stents as samples. The evaluation of hydraulic support economic efficiency is based on the seven indicators of Equipment life cycle cost, Equipment coal failure downtime of 10000 tons, Equipment operating rate, Equipment spare factor, Yield loss ratio, Equipment life per ton coal cost and Equipment life-span input-output ratio. Finally, we obtain the economical comparative analysis of the different mining height hydraulic supports. The seven economic indicators are as follows [5-6]:

Equipment life cost

$$
Q=(P+C+R) /(L \times 10000)
$$

$\mathrm{P}$ ——Equipment purchase price, based on the price in the asset management system (EAM);

$\mathrm{C}$ - — Equipment life and accessories consumption;

$\mathrm{R}$ - — Equipment life-cycle repairs and overhauls;

L- — - the amount of coal used during the entire life of the equipment, determine the actual amount of coal that has been scrapped on the same type of equipment.

Equipment million tons of coal downtime 


$$
T_{\mathrm{i}}=\frac{D_{\mathrm{g}}}{\mathrm{L}_{\mathrm{sh}}}
$$

$\mathrm{Dg}$ ———Equipment downtime caused by equipment failure so far;

Lash_—— the actual amount of coal used in the equipment to date.

Equipment operating rate

$$
W_{\mathrm{r}}=\frac{W_{\mathrm{a}}}{W_{P}}
$$

WA-—-Actual running time of equipment, WA=We-Dg-Ds;

$\mathrm{WP}-—-E q u i p m e n t$ planning run time, we $=\mathrm{Wt}$.;

WD-——Equipment supporting time;

T-——Work face effective boot production time, take 16h/d;

Dx_——Equipment preventive maintenance downtime.

Equipment spare coefficient

$$
K_{\mathrm{b}}=1+\frac{D_{\mathrm{d}}}{365 Y}
$$

Dd_—— Time spent on equipment repair and overhaul during the entire life of the equipment;

$\mathrm{Y}-$ — Equipment depreciation period, $\mathrm{Y}=\mathrm{L} /(330 \mathrm{Lt})$;

Lt_-—Equipment production coal.

Yield loss ratio

$$
S=\frac{N D_{\mathrm{g}}}{L_{\mathrm{sh}}}
$$

$\mathrm{N}$ - - Equipment actual production capacity.

Equipment lifespan tons of coal costs

$$
Q_{\mathrm{ch}}=K_{\mathrm{b}} Q
$$

Equipment life-span input-output ratio

$$
G=\frac{I}{O}
$$

$\mathrm{I}$-——Equipment lifespan investment, $\mathrm{I}=\mathrm{Kb}(\mathrm{P}+\mathrm{C}+\mathrm{R})$;

$\mathrm{O}-$ —-Equipment life span output $=[\mathrm{L} /(1+\mathrm{Ssh})] \times 540$;

Sash ——— Yield loss ratio, Sash $=[N D$ g/ $($ Lsh $\times 10$ 000) $] \times 100 \%$.

\section{Comparative Analysis of Economic Indicators}

For the 7 economic indicators mentioned above, we collect and calculate the relevant data for the hydraulic support. The Obtained comparison results of economic indicators of hydraulic supports at home and abroad of $3.5 \mathrm{~m}, 4.5 \mathrm{~m}, 5 \mathrm{~m}$ and $5.5 \mathrm{~m}$ respectively, as shown in Table 1 , Table 2, Table 3 and Table 4.

Table 1. Comparison of economic indicators for 3.5m hydraulic supports

\begin{tabular}{cccccccc}
\hline Specification & $\mathrm{Q}$ & $\mathrm{Ti}$ & $\mathrm{Wr}$ & $\mathrm{K}_{\mathrm{d}}$ & $\mathrm{S}(\%)$ & $\mathrm{Q}_{\mathrm{ch}}$ & $\mathrm{G}$ \\
\hline Domestic & 12.4 & 1.68 & 0.798 & 1.228 & 18.553 & 15.258 & $1 / 13$ \\
Abroad & 9.09 & 0.084 & 0.996 & 1.129 & 0.924 & 10.26 & $1 / 19$ \\
\hline
\end{tabular}


Table 2. Comparison of economic indicators for 4.5m hydraulic supports

\begin{tabular}{cccccccc}
\hline Specification & $\mathrm{Q}$ & $\mathrm{Ti}$ & $\mathrm{Wr}$ & $\mathrm{K}_{\mathrm{d}}$ & $\mathrm{S}(\%)$ & $\mathrm{Q}_{\mathrm{ch}}$ & $\mathrm{G}$ \\
\hline Domestic & 10.2 & 0.148 & 0.99 & 1.228 & 1.628 & 12.481 & $1 / 16$ \\
Abroad & 5.69 & 0.018 & 0.998 & 1.173 & 0.198 & 6.695 & $1 / 30$ \\
\hline \multicolumn{6}{c}{ Table 3. Comparison of economic indicators for $5 \mathrm{~m}$ hydraulic supports } \\
\hline Specification & $\mathrm{Q}$ & $\mathrm{Ti}$ & $\mathrm{Wr}$ & $\mathrm{K}$ d & $\mathrm{S}(\%)$ & $\mathrm{Q}_{\mathrm{ch}}$ & $\mathrm{G}$ \\
\hline Domestic & 8.2 & 0.505 & 0.935 & 1.226 & 5.56 & 10.05 & $1 / 20$ \\
Abroad & 5.30 & 0.025 & 0.997 & 1.168 & 0.27 & 6.19 & $1 / 32$ \\
\hline \multicolumn{6}{c}{ Table 4. Comparison of economic indicators for 5.5m hydraulic supports } \\
\hline Specification & $\mathrm{Q}$ & $\mathrm{Ti}$ & $\mathrm{Wr}$ & $\mathrm{K}$ & $\mathrm{S}(\%)$ & $\mathrm{Q}$ ch & $\mathrm{G}$ \\
\hline Domestic & 7.1 & 0.065 & 0.992 & 1.227 & 0.715 & 8.71 & $1 / 23$ \\
Abroad & 6 & 0.021 & 0.997 & 1.157 & 0.231 & 7 & $1 / 29$ \\
\hline
\end{tabular}

It can be seen from the comparative analysis of economic indicators that the economic efficiency of domestic hydraulic support is weaker than foreign hydraulic support. First of all, domestic-made hydraulic support costs more than the cost of life per ton of coal, explaining that the overall economic efficiency of domestic hydraulic support is worse than abroad. Among them, the cost difference of the life span of $4.5 \mathrm{~m}$ hydraulic supports is the largest, the domestic $4.5 \mathrm{~m}$ hydraulic support is $43.94 \%$ higher than the foreign $4.5 \mathrm{~m}$ hydraulic support. The $5.5 \mathrm{~m}$ hydraulic support has the smallest difference, however, 5.5m domestic hydraulic support is also $15.49 \%$ higher than foreign hydraulic support. Secondly, economic indicators for measuring the reliability and stability of the hydraulic support such as 10000 tons coal failure downtime, Equipment operating rate, Equipment spare factor and yield loss ratio, all domestic series of hydraulic support are weaker than foreign hydraulic support, it shows that the failure rate of domestic hydraulic support is higher than that of foreign hydraulic support. Therefore, maintenance costs, spare parts costs and loss of production due to equipment failure are higher than those of foreign hydraulic supports. This is also a key factor that causes the economic efficiency of domestic hydraulic support to be weaker than foreign hydraulic support. Finally, due to the high failure rate of domestic hydraulic supports, the cost per unit of life of the domestic hydraulic support equipment and the input-output ratio must be higher than that of the foreign hydraulic support.

Through the above comparison, it is not difficult to find that the weak economy of domestic hydraulic support is mainly caused by its high failure rate, which is the low reliability and stability of domestic hydraulic support.

\section{Conclusion}

Compared with foreign hydraulic supports, domestic hydraulic supports have relatively low initial purchase costs, but due to the high failure rate and poor reliability of domestic hydraulic supports, the consumption of their parts and materials is much greater than that of foreign hydraulic supports, and the cost of overhauling domestic hydraulic supports is higher than that of foreign hydraulics. The high repair fees result in negligible gap in the life-cycle cost between domestic hydraulic supports and abroad.

\section{References}

[1]. Li Ailin.On the Present Situation and Developing Direction of Hydraulic Support and Technology in China [J]. Energy and energy conservation, 2016(1):33-35. 
[2]. Wang Qigong, Li Binge, Huang Jiaxing. Mining Machinery and Supporting Equipment [M].China University of Mining and Technology Press, 2006.

[3]. Zhang Jajuan. Hydraulic Support [M]. Beijing: Coal Industry Press, 1985.

[4]. Cao Lianmin.Study on manufacturing technology of hydraulic powered support [J]. Coal Science and Technology, 2016, 44(04):83-88.

[5]. Yang Chenglong.Economy Evaluation Method of Equipment of Excavation [J]. Coal Mine Machinery, 2010, 31(12):225-226.

[6]. Zhang Aachen, Guo Bunkum. Effective Access to Improve Economy of Mining and Excavation Equipment [J]. Coal Economic Research, 2013, 33(04):83-85. 